This is an author produced version of a paper published in Agroecology and Sustainable Food Systems.

This paper has been peer-reviewed but may not include the final publisher proof-corrections or pagination.

Citation for the published paper:

Jan-Olof Drangert, Barbara Kiełbasa, Barbro Ulen, Karin S. Tonderski \& Andrzej Tonderski. (2017) Generating applicable environmental knowledge among farmers: experiences from two regions in Poland. Agroecology and Sustainable Food Systems. Volume: 41, Number: 6, pp 671-690. http://dx.doi.org/10.1080/21683565.2017.1310786.

Access to the published version may require journal subscription. Published with permission from: Taylor \& Francis.

Standard set statement from the publisher:

"This is an Accepted Manuscript of an article published in Agroecology and Sustainable Food Systems on March 31 2017, available online: http://www.tandfonline.com/10.1080/21683565.2017.1310786 ."

Epsilon Open Archive http://epsilon.slu.se 


\title{
Generating applicable environmental knowledge among farmers experiences from two regions in Poland.
}

\author{
JAN-OLOF DRANGERT ${ }^{1}$, BARBARA KIEŁBASA ${ }^{2}$, BARBRO ULEN ${ }^{3}$, \\ KARIN S. TONDERSKI ${ }^{4}$, and ANDRZEJ TONDERSKI ${ }^{4}$ \\ ${ }^{1}$ VATEMA Co., Stockholm, Sweden ${ }^{2}$ Department of Agriculture and Economics, University \\ of Agriculture, Krakow, Poland \\ ${ }^{3}$ Department of Soil and Environment, Swedish University of Agricultural Sciences, Uppsala \\ Sweden, ${ }^{4}$ POMInnO Sp. Zo.o., Gdynia, Poland
}

\begin{abstract}
Raising environmental awareness among farmers is the key to successively reach environmental goals. The present study assessed the knowledge development process and the raised environmental awareness among 30 farmers from Poland exposed to four approaches aimed to reduce phosphorus $(P)$ and nitrogen $(N)$ losses to water. The farmers were interviewed with open-ended questions on-farm both before and after the project intervention. As expected, the farmers attempted to adjust their farm practices to the European Union regulations, which are in some cases supported by subsidies. As a complement, the project offered tools for system-thinking based on farm data and supported by agricultural advisors: i) a survey of plant-available $P$, potassium $(\mathrm{K})$, magnesium $(\mathrm{Mg})$ and soil $\mathrm{pH}$, resulting in soil maps; ii) assessment of nitrogen leaching risks from individual fields; iii) compilation of a farm-gate balance. . Farmers were positive to soil surveys and maps, but had limited understanding of the nutrient balance concept and calculations. They generally relied on their own experiences regarding fertilisation rather than on calculated farm nutrient balances and leaching risks. Farmers' understanding and willingness to adopt new approaches to improve nutrient efficiency and reduce negative environmental impacts is discussed.
\end{abstract}

KEYWORDS Baltic Sea; environmental protection; farm nutrient management; Poland

\section{Introduction}

In the past, environmental issues have rarely been a focus for agricultural advisory services. However, since Poland joined the European Union (EU) in 2004, environmental requirements have been introduced as part of the EU support system and these have had great impact on farms (Council Regulation No. 1698/2005). New requirements expected to come into force in January 2017 include constructing suitable storage for animal slurry on livestock farms with more than 10 livestock units and arable area $>10$ ha, to allow slurry to be stored over winter. At the same time, the EU Nitrate Directive (91/676/EEC) will be extended from minor areas to cover the entire agricultural area in Poland.

From a northern European perspective, it is important to arrest eutrophication of the Baltic Sea. Eutrophication is largely caused by food production and human food consumption 
generating runoff water and wastewater containing high concentrations of nutrients (Ulén and Kalisky 2005). Pollution of local water bodies in rural areas, including household water sources, is targeted by environmental policies, but better practical knowledge among farmers about rational management of nutrients on the farm is also required. The base is to know how nutrients flow on the farm and where they come from, as this determines the sustainability of the farm to a large extent (Hendrix et al. 1992).

Knowledge is commonly transferred to European farmers through official advisory services, and this is also the case in Poland (AKIS, 2012). In recent decades, seed and fertiliser companies have also begun to provide such services, but with the focus on production and rarely on environmental issues. The work of agricultural advisors is gradually raising environmental awareness among farmers and increasing their understanding of how farming activities impact the Baltic Sea ecological status. Knowledge of the problem itself is also improving over time, with uptake of new information being influenced by farmers' practical experiences and by research and media coverage. Agricultural advisory services can benefit from cooperating with research institutions in order to transfer research results in a way that suits the agricultural community and their farming practices (Agrotec and Evaluators, 2009).

In the three-year project presented here, a sample of 50 Polish farmers was provided with information and tools for sustainable management of nutrients. The aim was to explore and capture farmers' knowledge and attitudes (understanding) of various agricultural practices designed to reduce environmental degradation and improve sustainability. Nutrient losses were a prime concern, since they harm water bodies and also cause economic losses. The project explored measures the farmers have taken to improve farm and fertiliser management and their willingness to adopt new proactive measures on their own farms.

As the main project input, official agricultural advisors in the sample areas were trained to perform farm-gate nutrient balance calculations, assess the risk of nitrogen losses on individual fields, assess farm hotspots for nutrient losses together with the farmers concerned and conduct soil surveys. These practices were implemented during repeated farm visits by the advisors. The project outcomes were assessed by holding pre- and post-project interviews with farmers and by asking advisors to complete a post-questionnaire about their perceptions and knowledge of practical methods to improve environmental sustainability. This paper presents the findings of these interviews and surveys and makes some recommendations for future environmental activities.

\section{Generation and adoption of knowledge}

Hassard and Kelemen (2002) define knowledge as "a group of cultural practices inextricably embedded in the social and physical conditions in which they are produced and used". Knowledge accumulates with growing experience in every individual, but the process may be difficult to clearly identify or explain (Nonaka and Nishiguchi, 2001). This knowledge acquired over time, called tacit knowledge (Polanyi, 1966; Brokensha et al., 1980), is used by people in everyday actions, but may be difficult to formalise. It is characterised by greater practicality than its antonym explicit knowledge, and may therefore be easier to discern in actions than in explanations (Ambrosini and Bowman, 2001).

Tacit knowledge can be augmented mainly through participation and pro-active methods (Swanson, 2008). In addition, transfer of knowledge is impeded when new generations enter as old farmers retire. The method of creative problem-solving can be used, as can engaging farmers in experiments or research and promoting "learning-by-doing" methods (Taylor 2007). Discussions and group meetings may also play a role in transfer of tacit knowledge. 
Explicit knowledge, in contrast, is relatively easy to formalise and transfer using various techniques, such as formal training sessions (Nonaka and Krogh, 2009). However, such methods may not be as efficient in promoting practically applicable knowledge.

Over the years, many attempts have been made by researchers to describe the learning process and what it takes to transform knowledge into action. Some researchers divide the target group into categories such as early adopters, laggards (those who need repeated information and/or a long time for reflection between message and knowledge), and late adopters to explain varying success rates (Lionberger, 1961; Rogers, 1986). Others focus on facilitating the learning process to pass on messages, so that target groups are prepared to adopt ideas and methods. In the present context, the challenge is to adapt and incorporate environmental awareness and knowledge into everyday practice.

It is generally recognised that acquisition of knowledge is not always sufficient to generate action and that target group members may do the right thing without knowing why it works. Everett Rogers (1986) comments in general (and not about agriculture in particular) that "in the past we may have severely underestimated the degree to which the user system was capable of managing its own knowledge transfer process. Our understanding of decentralized diffusion systems is still limited, owing to the general lack of investigations of such user-dominated diffusion". Unsurprisingly, most evaluations, assessments and appraisals of agricultural development activities focus on external interventions and hence are biased towards agent-induced activities, such as provision of cheap credit for farm mechanisation and introduction of subsidies for catch crops.

Schon (1971) made the important point that a need does not necessarily precede ideas of innovation, unless it is a question of very small changes. The probability of action being taken may be lower if the potential actor is satisfied, but is not negligible if e.g. a favourable opportunity arises. On the other hand, the persistence of behaviour is not necessarily attributable to any particular "resistance to change", but simply to the absence of a vigorous search for new alternatives under circumstances where the existing situation is regarded as satisfactory. Within this open situation, it is necessary to identify potential supporting and obstructing factors to dissemination and use of knowledge.

In such an environment, knowledgeable agricultural advisors could function as "brokers of knowledge" (Klerkx, Hall and Leeuwis, 2009). The diffusion of agricultural knowledge is often closely linked to its practical application and therefore depends on how easy it is to operationalise (Kiełbasa and Kania, 2014). Hence, the task of incorporating information and knowledge "has to overcome the gap between research and practice" (AKIS, 2012). The project described in this paper focused on generation of new knowledge and ways to convert this into action or behaviour changes.

\section{Materials and methods}

A sample of 30 farmers was selected from the 50 farmers involved in the project. They represented crop farms producing cereals only, dairy and pig farms with mainly animal production, and mixed farms with both livestock and crop production. Half the farms were situated in the NW Mazovia region near Warsaw, and half in Pomerania, near the Baltic Sea. Farm sizes varied from 13 ha to 150 ha, with an average of 45 ha. All farmers were males, with the mean age 45 years but including some young farmers and some nearing retirement.

The farmers were interviewed on two occasions (2013 and 2015) using a protocol with semi-structured questions. Each interview took about $1.5 \mathrm{~h}$ and was conducted in the farmer's home. The interviews were audio-recorded with the consent of the interviewees and the transcripts were analysed jointly by the interviewer and the principal investigator. The first 
round of interviews explored farm conditions and farmers' perceptions and knowledge of nutrient management and environmental issues (Drangert 2014). By the time of the second interview, each farmer had received the results from the soil survey and had calculated their farm-gate nutrient balance (FGB) and field nitrogen leaching risks with the help of their local advisor. They had also walked around the farm together with the respective advisor to identify hotspots for nutrient losses. The second round of interviews scrutinised aspects identified in the first interview, in order to capture recent changes in management (Drangert and Kiełbasa, 2016).

The research project singled out public agricultural advisors as the 'vehicle' for transferring knowledge from project staff to farmers. In an attempt to assess attitudes and knowledge among advisors, they were given a questionnaire on nutrient cycling and their relations with the interviewed farmers. The ensuing analysis sought to assess advisors' interests and identify their role in transferring information and knowledge (Drangert and Kiełbasa, 2015).

\section{Findings from the interviews}

Most farmers interviewed were in the process of changing from smallholders with limited contact with the market to managers of commercial, highly mechanised farms. Several stated that they needed to develop their business, which requires a range of skills and knowledge. The demand to include environmental aspects of farming and animal husbandry activities is likely to require further adaptation in order to comply with EU requirements, although this was not clearly stated in the interview responses.

The farmers reported a substantial increase in crop yield, often double the level a decade ago, mainly achieved through: application of mineral fertiliser (nine interviewees in Mazovia $(9 \mathrm{M})+12$ in Pomerania $(12 \mathrm{P}))$, manure $(9 \mathrm{M}+10 \mathrm{P})$, lime $(1 \mathrm{M}+2 \mathrm{P})$, new crop varieties $(4 \mathrm{M}$ $+7 \mathrm{P})$, improved seeds $(3 \mathrm{M}+1 \mathrm{P})$, plant protection measures $(5 \mathrm{M}+6 \mathrm{P})$, improved knowledge $(5 \mathrm{M}+4 \mathrm{P})$, changed methods of cultivation $(4 \mathrm{M}+5 \mathrm{P})$, and improved machinery and equipment $(4 \mathrm{M}+0 \mathrm{P})$. Surprisingly, only four interviewees mentioned technology, despite extensive mechanisation of their farm work (Drangert 2014).

In a Polish perspective, the farms managed by the interviewees are large (average 45 ha including leased areas), and therefore these farmers may be more market-orientated than the average Polish farmer with a 12 ha farm.

Knowledge and perceptions among this category of farmers are important since they may reflect future trends during continued enlargement of Polish farms. The farmers reported a readiness to meet challenges from changing markets for agricultural products, but were weary of bureaucratic regulations. The farmers would like to, but cannot, influence the market for their produce. Many have therefore tried to improve their farm business by investing in modern equipment and increasing the acreage, but are now burdened with loans, which hampers further investment. They are left with essentially two options in management: lowering their operating costs or engaging in additional activities on/off the farm.

Some interviewees had abandoned pig and dairy farming and had switched to beef cattle. Others had extended into vegetable and fruit production for local markets. One farmer had opened an agricultural machine rental service, while another produced packs of birdseed.

The Mazovian farmers seemed to be more inclined to undertake entrepreneurial efforts than the farmers in Pomerania. They had expanded their farm area substantially more in the last few decades (had tripled the farm area, compared with a doubling in Pomerania), partly because there were more fields for lease or purchase available in Mazovia. A stark difference was that four farmers in Mazovia had engaged in additional non-farm activities, whereas no Pomeranian farmer had done so. The Mazovian farmers had better access to the markets and 
possibly better opportunities to sell their products. However, farmers in both regions stated that the main reason for not engaging in additional non-farm activities was bureaucratic regulations.

The interviewees reported that they weigh up positive and negative economic outcomes when considering changes in farm management. They consult their family, but the male always makes the final decision. They rely largely on their own experience when managing the farm in a changing world. Therefore, it can be said that they generally use tacit knowledge when running the farm. This tacit knowledge is acquired through discussions with other farmers or family members. The farmers' own success and failur as a producer is another important factor for his management choices.

\section{Concerns about fertiliser management}

The cost of mineral fertilisers is rising and already comprises a substantial proportion of total farm expenditure. Therefore, the farmers interviewed expressed an interest in shifting to more cost-effective management of fertilisers. This would require knowledge of the nutrient content of different kinds of manure, the concentrations of plant-available nutrients in the soil and the plant requirements during different phases of growth. Ten of the 15 farmers in the Mazovia region and 12 of 15 farmers in Pomerania combined arable and animal farming, while the others did not raise any animals. The interviewees reported that they prefer manure to other fertilisers, despite the workload and transport cost to distribute manure to scattered fields. Their reasoning is shown in the decision-making process in Figure 1.

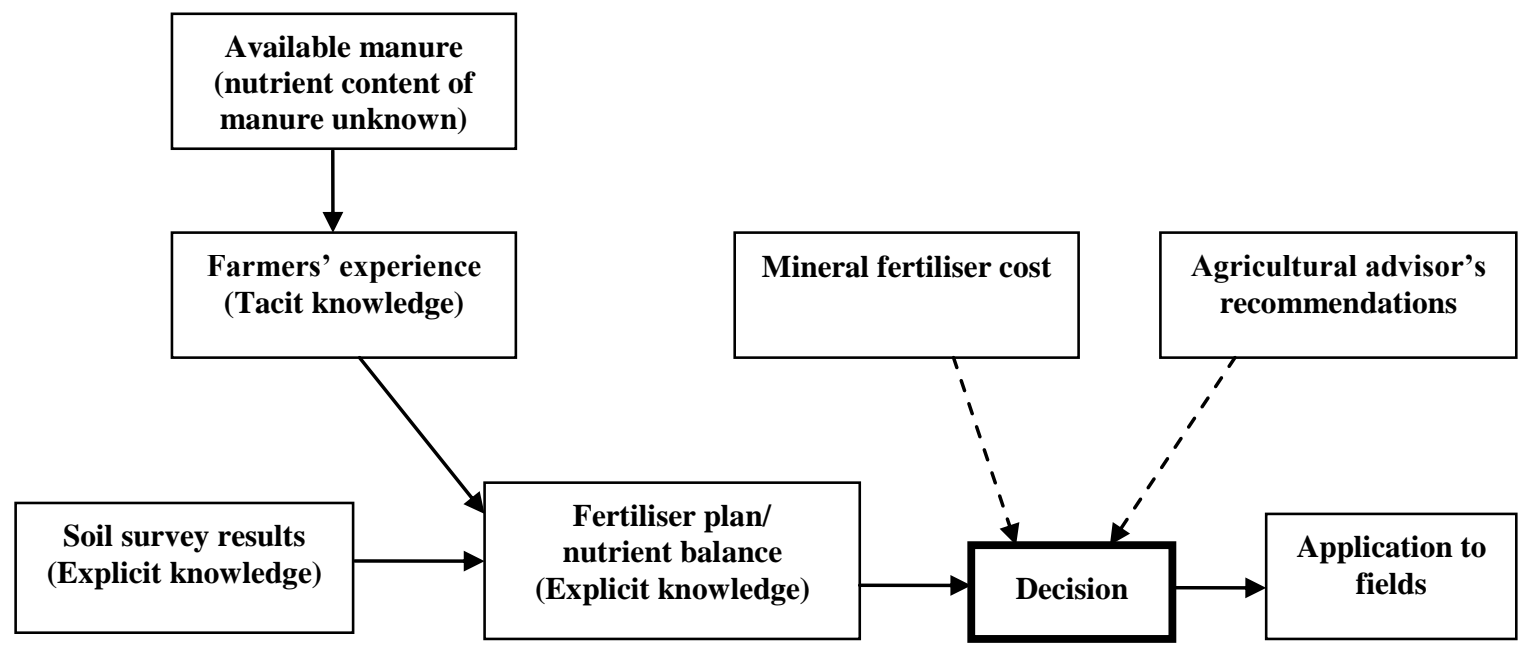

Figure 1. Interpretation of the decision-making process used for fertiliser management on interviewees' farms.

First, they estimate how much manure they have and decide how to distribute it between fields. On livestock farms, some 20-25 tons of manure are applied per hectare every 3-5 years in order to meet the needs for most crops and to concentrate the work and transport costs to one occasion. Little additional manure is available on the market, since animal producers generally use their manure to fertilise their own fields.

Recent data on the nutrient content of different kinds of manure are lacking, but the European Union has requested all Member States to produce such information by 2016. In essence, the farmers interviewed rely on their experience and their own observations when it comes to doses of manure and mineral fertilisers. They apply the conventional dose without 
knowing the details of its nutrient content. However, they also consider the general nutrient requirements of the planned crop. As regards nutrient availability in the soil, the farmers lack data except for occasional soil survey results. They are reluctant to conduct many soil analyses due to the high costs. Soil concentration of nitrogen $(\mathrm{N})$ in mineral form is highly variable over the season and hence not included in standard soil surveys, which include $\mathrm{pH}$ and available phosphorus $(\mathrm{P})$, potassium $(\mathrm{K})$ and magnesium $(\mathrm{Mg})$.

Phosphorus is excreted in faeces, while most $\mathrm{N}$ and $\mathrm{K}$ are found in the urine fraction. The relative proportions of $\mathrm{N}$ and $\mathrm{P}$ in manure are imbalanced compared with the requirements of common agricultural crops. A simple calculation using an application rate of $190 \mathrm{~kg} \mathrm{~N} / \mathrm{ha}$ and year (maximum $\mathrm{N}$ application to comply with the EU Nitrate Directive) and $20 \mathrm{~kg} \mathrm{P} / \mathrm{ha}$ and year (amount commonly removed with a good cereal yield) demonstrates that application of manure from 1.5 dairy cows can supply the required amount of $\mathrm{P}$ per ha, but that more $\mathrm{N}$ needs to be added either from mineral fertiliser or gained by biological fixation. Manure from 14 pigs supplies $130 \mathrm{~N} / \mathrm{ha}$ and year but also supplies substantially more (+40\%) $\mathrm{P}$ than is required by the crop. A comparison of livestock density and farm size in the study regions (Drangert 2014) showed that most of the farmers with dairy cows produce enough manure with its content of $\mathrm{N}, \mathrm{P}$ and $\mathrm{K}$ for their on-farm crops, regardless of what they grow. In contrast, the pig farmers produce far less manure than they need for their crops (except for two with a livestock density of more than 2.2 livestock units (LIU) per ha). Most pig farmers in this study therefore had to complement with mineral fertilisers.

Regarding best practice to maintain soil fertility, the interviewees advocated a mix of three or more methods from a range including applying manure and mineral fertilisers, liming, growing catch crops, using a proper crop rotation and leaving crop residues in the field. Given the farmers' limited knowledge of nutrient content and mobility in soil, they were asked about the impact of man-made disturbance of the soil. The interviewees were aware that ploughing down crop residues improves soil properties by increasing the content of carbon and nutrients and simultaneously speeds up mineralisation, primarily of N. However, six farmers claimed that ploughing simply mixes $\mathrm{N}$ and $\mathrm{P}$ with the soil, while three other farmers stated that ploughing leaves no fertiliser components on the surface. Eleven farmers were convinced that ploughing is not best practice and has drawbacks such as disturbing the soil too much or impeding plant nutrient uptake. Six farmers stated that there are losses of nutrients from ploughing, e.g. fertiliser gets lost to the air or to water courses via runoff after rainfall. Five farmers had abandoned ploughing or did it rarely.

It is beneficial to plough in spring instead of autumn to reduce nutrient losses from bare soil during winter. This was most clearly expressed by farmers in Mazovia, who farm in areas classified as nitrate-sensitive. However, the farmers in Pomerania were more reluctant to use spring tillage because the climate there is wetter and in some areas the soils are clayey. In those areas, soils may be too wet in spring and then tractor driving can increase soil compaction problems.

Every third farmer advocated growing catch crops (crops that take up $\mathrm{N}$ before and during periods when the main leaching takes place and are later ploughed down in the soil) such as lupin, phacelia and mustard, but these farmers were primarily in Mazovia (Drangert, 2014). However, no one in this area availed of the opportunity to test the free catch crop seed offered by the project. The dry weather in the study year might have been one reason for this.

The farmers were eager to know their soil $\mathrm{pH}$ values in order to apply appropriate doses of lime. Through the project, they had gained the information that a higher soil $\mathrm{pH}$ increases the availability of soil-bound $\mathrm{P}$ to plants. They were convinced that applying lime is cheaper than adding $\mathrm{P}$ to acid soils in order to increase yields. 


\section{Perception and knowledge of nutrient flows and losses}

Farmers' individual perceptions of $\mathrm{N}$ and $\mathrm{P}$ flows on their farm varied. In order to capture farmers' sense of $\mathrm{N}$ and $\mathrm{P}$ flows and sinks on the farm, they were asked to rank the magnitude of six flows of $\mathrm{N}$ and $\mathrm{P}$, respectively, to and from a field/farm (Figure 2).

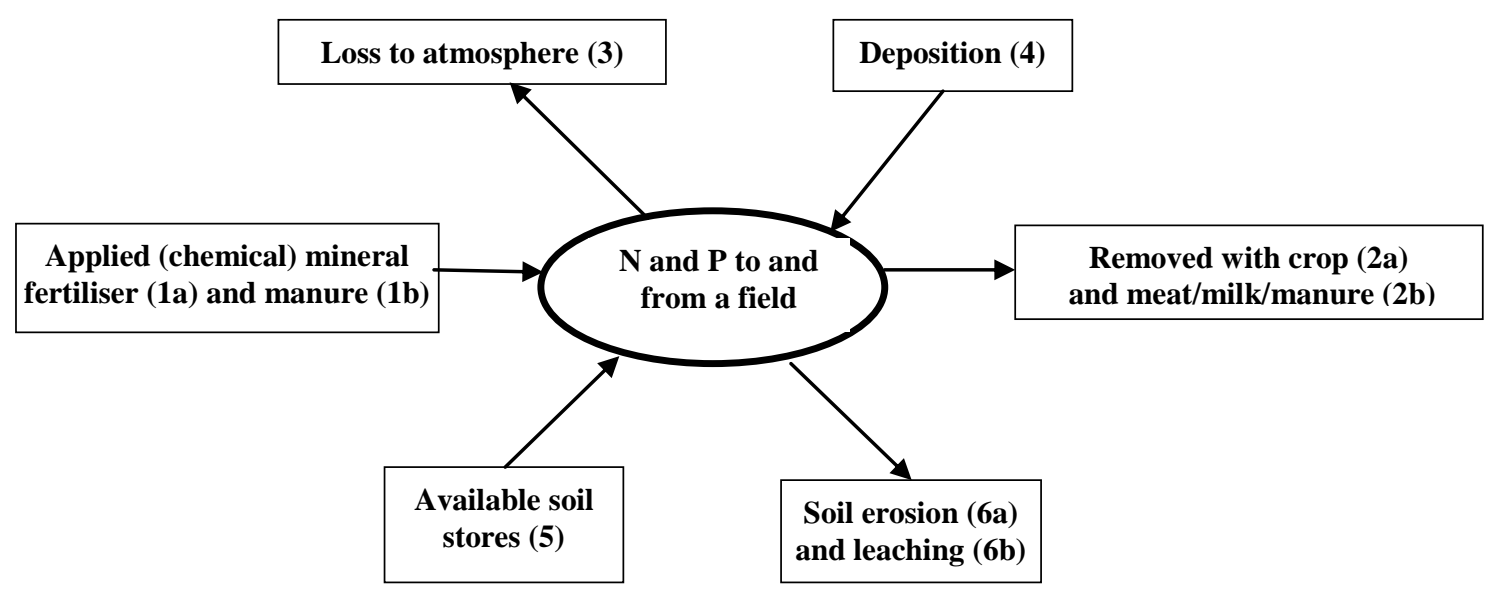

Figure 2. Nitrogen $(\mathrm{N})$ and phosphorus $(\mathrm{P})$ flows in a field. Illustration used in the interviews with farmers.

The interviewees viewed this holistic presentation of nutrient flows as incomplete because the actual flows depend on the type of farm, crop grown and so on. However, $60 \%$ of the interviewees ranked the following four $\mathrm{N}$ and $\mathrm{P}$ flows as most important: (1a) Chemical fertiliser $>$ (1b) manure $>(2 a)$ removed with the harvested crops $>$ (2b) removed with meat/milk/manure. This shows that the input of nutrients is considered larger than the removal. Ten farmers proposed exactly the same ranking order for all $\mathrm{N}$ and $\mathrm{P}$ flows, indicating that their tacit knowledge wrongly perceived the magnitude of the flows of the two elements to be similar.

Some of the responses were: "It all depends on many factors and shouldn't be standardised."; "In fact, there are many factors that affect nutrient flows on the farm, and a lot depends on e.g. rainfall, temperature and other weather or crop factors."; "Most nutrients are introduced with fertilisers. Most come out with crops and agricultural products."; "There is no erosion in my area. Nitrogen needs to be applied regularly, because it is volatile and evaporates to the air."; "There's no deposition process."; "Everything depends on the prevailing atmospheric conditions and the agro-technology."; "The main flow is fertilisers together with manure. In my opinion, it results in the largest yield."; "The flows are much the same for nitrogen and phosphorus." One farmer said that it is not possible to rank the flows because so many different factors influence them.

An important part of the project was to understand farmers' perceptions of their impact on the environment. Therefore interviewees were asked to comment on two pictures which might spark thoughts about nutrient losses. The first picture showed an open drainage ditch that could receive nutrients, mainly nitrates, through leaching and transport them to larger water bodies (Figure 3). Such transport of nutrients with surface water contributes to eutrophication of water bodies downstream, including the Baltic Sea (Drangert and Kiełbasa, 2015). 


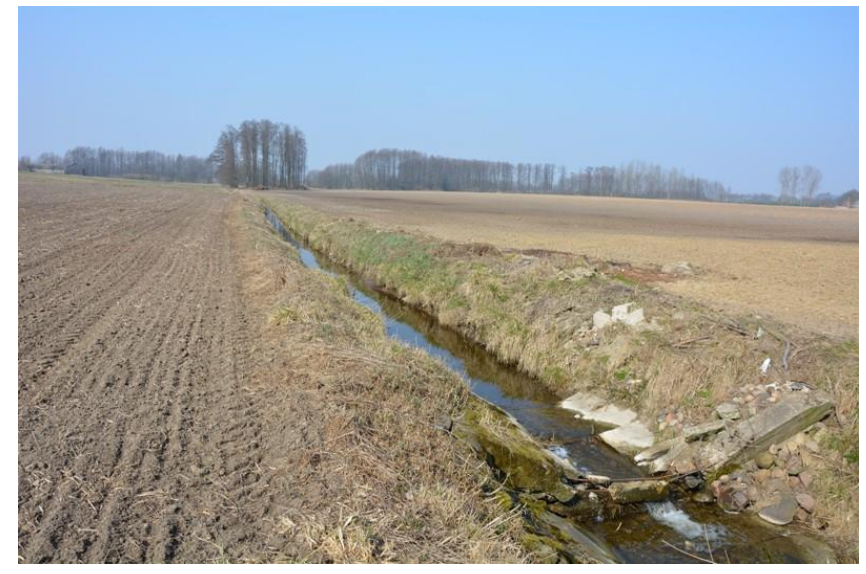

Figure 3. Drainage ditch photo shown to the farmers interviewed in the study (Photo: B. Ramnerö).

Fourteen of the interviewees commented on the open agricultural ditch, and all but one thought its management was neglected. However, the farmers' detailed responses varied considerably. Most farmers said that the ditch is not well maintained. Some of the others claimed that it should be re-dug because it is too shallow. They said that the shape of the ditch is irregular and it looks sloppy. Some farmers were less critical and said that fertilisers probably do not get into the water because it is not very neglected as it is not overgrown with plants or weeds.

Nine farmers commented on the risk of nutrient losses: four noted that there was a buffer zone preventing runoff of nutrients, while another four said a buffer zone was lacking. Some farmers claimed that setting aside buffer zones compromises production, but agreed that it is advisable to construct buffer zones to reduce water pollution. Some farmers were aware that there should be a grass strip, which would prevent direct runoff of fertilisers and pesticides into the ditch. Another five farmers mentioned that they observed leakage and polluted water in the photo. One farmer said that the rain had washed the nutrients into the soil and further to the ditch.

The second picture shown to farmers depicted a manure pile and was assumed to inspire comments about potential problems of nutrient leakage and losses (Figure 4).

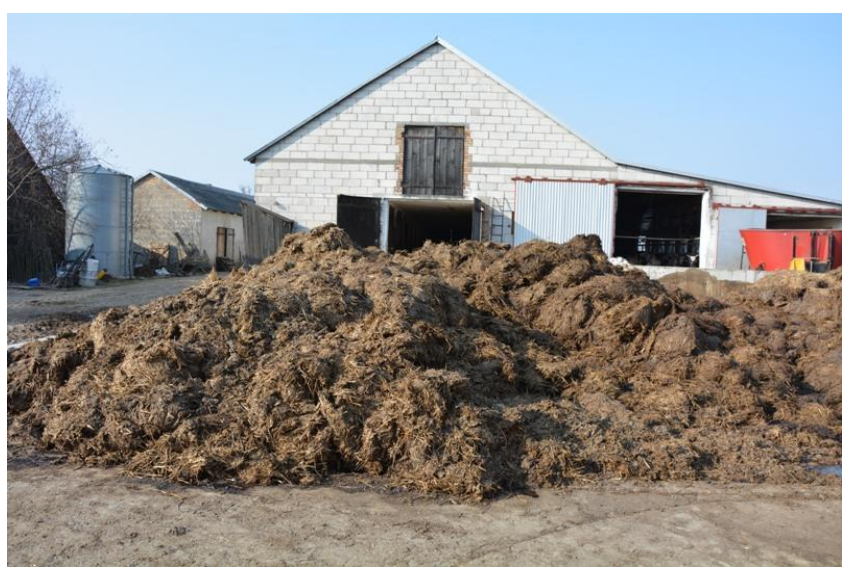

Figure 4. Manure stored on a pad outside an animal house. Photo shown to the farmers interviewed in the study (Photo: B. Ramnerö). 
The picture of the manure heap proved to be insufficiently clear, as 12 farmers said that the manure is stored on a pad, seven said there is no pad and five were uncertain. The important response is that all claimed that there should be a pad to prevent nutrient losses to soil/groundwater and the atmosphere. Two farmers also insisted the pad should have walls.

The comments on the pictures showed that the farmers were quite aware of nutrient losses, the local environmental consequences and potential economic losses. That awareness was likely a result of the EU regulations and subsidies for environmental measures. Most interviewees mentioned measures that are in line with the EU recommendations. However, very few associated the manure storage system and buffer zones with eutrophication of water courses, including the Baltic Sea.

In the post-project interviews, $28 \%$ of the farmers in Pomerania stated that they had introduced or aimed to introduce one or two of the following measures, directly aimed at reducing nutrient leaching, based on the soil survey and the farm walk: improved manure storage, use of fertiliser plans, avoiding soil tillage on steep slopes and including a catch crop in the crop rotation. In Mazovia, nutrient analyses of the farm's own manure were encouraged by the regional advisors and the results, together with the soil maps, were used for planning fertilisation. In this region with its dry climate, no farmer was interested in free catch crop seeds since they were afraid the catch crop would compete for water with the main crop, resulting in reduced yields.

\section{Tools for creating environmental knowledge among farmers}

In this project two main tools, a soil survey and farm-gate nutrient balance, were offered for free to give farmers access to applicable knowledge and information for their own selfevaluation of their farm. These tools are useful to agricultural advisors when developing a crop rotation and fertiliser plan jointly with farmers.

The input data for the tools were analyses of soil samples and literature data on crop fertiliser requirements, the nutrient content of agricultural products and manure, nitrogen fixation and deposition. The soil survey offered included soil $\mathrm{pH}$ and available amounts of $\mathrm{P}$, $\mathrm{K}$ and $\mathrm{Mg}$. The advisors took soil samples on their first visit to the farm and these were analysed in regional accredited laboratories. The results were presented as 'soil maps' with different colours indicating the nutrient status for $\mathrm{P} / \mathrm{K} / \mathrm{Mg}$ and the $\mathrm{pH}$. The $\mathrm{pH}$ values were converted to indicate the need for liming in the field. Figure 5 shows an example of $\mathrm{P}$ status and liming requirements on one farm. 


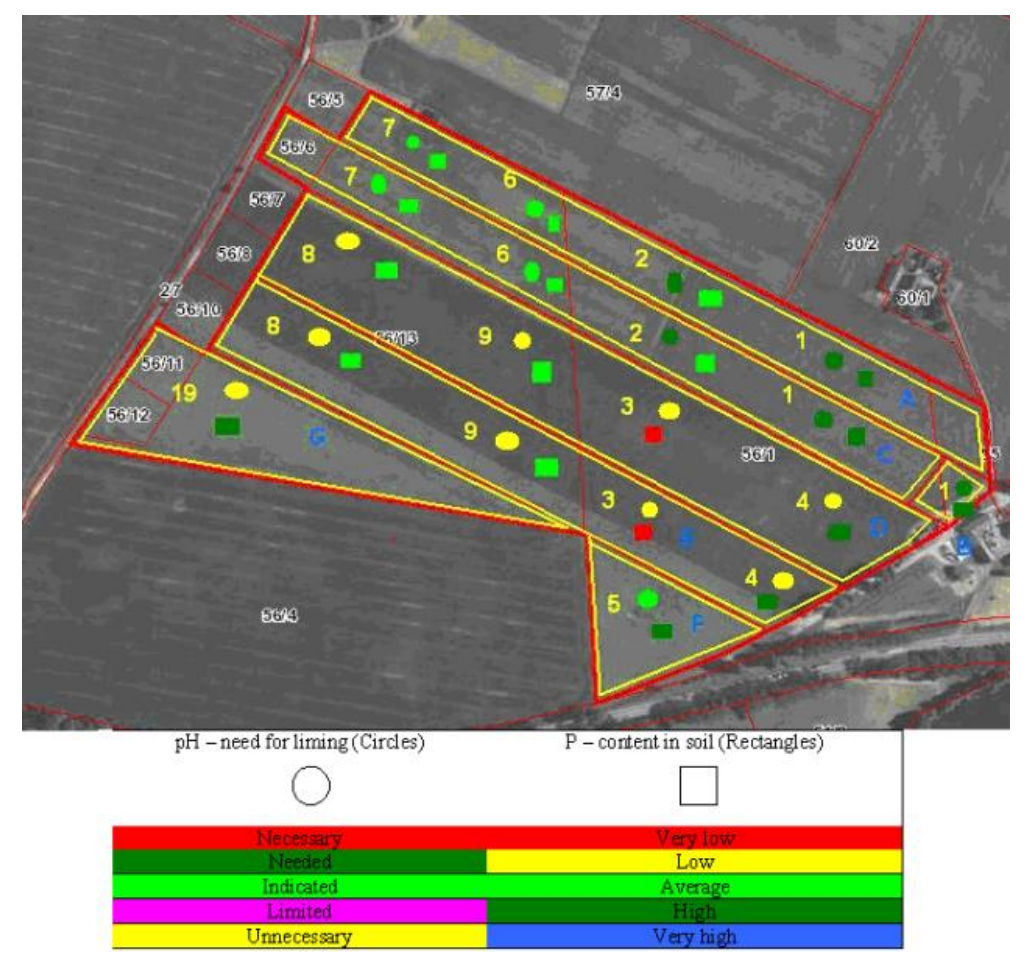

Figure 5. Map of soil phosphorus (P) status and associated liming requirement on fields of one farm included in the study (Source: K. Radtke, PODR Gdańsk).

The farmers viewed the soil maps as a simple and very useful tool for determining the fertiliser dose on specific fields. One farmer even framed the map and hung it on the wall in the farm house. This tool thus represents a step forward in achieving efficient nutrient management.

The next step in managing the nutrients on the farm is to create a farm-gate nutrient balance (FGB), which accounts for all the inputs and outputs. Inputs include feedstuffs, bought animals, mineral fertilisers, bought manure, atmospheric deposition, soil microbe Nfixation and other inputs (seeds, bought straw, etc.). Outputs include animal products (animals, meat, milk, eggs, manure, etc.), plant products (catch crops, straw, silage etc.), leachate, and losses to the atmosphere (Oenema and Pietrzak 2002).

The rather vague ideas farmers had about nutrient flows on the farm, as uncovered in the interviews, were then compared against farmers' perceptions of the value of FGB calculations. Of the 28 farmers interviewed on this issue, 23 claimed to recall the farm-gate balance more or less well. As a result of the farm-gate and $\mathrm{N}$ leaching module calculations, six farmers had changed activities such as less ploughing, reduced application of mineral fertilisers with NPK or just N, and one had achieved "the best yield ever" after such changes. Another nine farmers stated that they did not need to act, since the calculations showed that their farms had a balanced nutrient situation. Two farmers did not trust the results and therefore relied on their own experience.

As mentioned, two other tools were also tested in the project: an Excel spreadsheet (including agricultural management and crop rotation) to estimate $\mathrm{N}$ leaching risks from individual fields, and a farm-walk discussion between the farmer and an advisor about improved nutrient management and other measures that could be introduced to reduce nutrient losses from hotspots such as farmyards or erosion-prone areas. 
All these tools were intended to support the process of implementing new knowledge to improve nutrient management on farms. The impact of the tools was generally modest in this first year, and will require several years to become part of farmers' active toolbox.

\section{Discussion}

This project employed the method of engaging agricultural advisors to disseminate environmental knowledge and to suggest remedial measures to farmers. The underlying assumption was that advisors have sufficiently high status and trust among farmers to carry out this work. Advisors may gain high status through various means, such as acting as brokers of resources for the farmers, being well-trained and/or having personal experience of farming. Success in this respect is a real challenge for the whole advisory system.

The advisors support farmers to apply for EU subsidies and to write reports. This work is highly appreciated by farmers, according to their interview responses. It is likely that farmers viewed the research project in the same way, i.e. as resources made available by advisors. The project provided lime, soil surveys, access to a farm-gate nutrient balance and a detailed farm walk with the advisor.

Farmers know about the positive yield effect of applying lime on their acid fields and half of those interviewed had used lime before the project started. However, neither the advisors nor the farmers were well informed about why liming improves yield. The reason is that liming raises the soil $\mathrm{pH}$, which in most cases reduces the chemical adsorption of $\mathrm{P}$ to soil particles, allowing plant roots to take up more $\mathrm{P}$ from the soil solution. In the project, liming was subsidised by $26 \%$ in Pomerania and $50 \%$ in Mazovia (where there were fewer farms with acid soils). Dissemination of knowledge about the benefits of liming is quite straightforward and is successful due to a positive experience and cost savings, irrespective of the level of scientific knowledge.

A future concern is which type of advisor farmer should consult. Official agricultural advisors will possibly propose liming and sellers of lime will undoubtedly do so, while it is unlikely that fertiliser sales advisors will advocate liming. This constitutes a real problem, in particular in cases where the latter have a good rapport with farmers. Such a conflict of interests can be avoided if farmers are familiar with their soils and conversant with $\mathrm{N}$ and $\mathrm{P}$ flows and balances.

Soil surveys provide information about $\mathrm{pH}$ and the availability of some macronutrients in the soil, which is much appreciated by farmers. Most of the interviewed farmers had some soil analytical data from previous testing. They used the new data to plan the doses of various fertilisers. Farmers also already had fair knowledge of other factors, such as plant requirements and previous years' doses. It is easy for advisors to encourage the use of free soil surveys since farmers are positive to receiving such data and are prepared to allow it to influence their fertiliser management.

The examples of the subsidized liming and soil survey represent what Schon (1971) calls 'favourable opportunity'. However, acceptance of the results from a farm-gate nutrient balance (FGB) calculation does not seem to depend on favourable opportunity. The calculation of FGB demands knowledge, as does interpretation of the results/outcome. However, during the training of advisors it was found that few were conversant with FGB and several faced difficulties in filling in the Excel spreadsheets. Most advisors were not in a position to assess whether the FGB results obtained were reasonable, and therefore a counting error could lead them to suggest applying too much or too little P or N. In interviews, farmers mentioned their first challenging encounter with FGBs and some complained that advisors had given incorrect advice. In this case, the new tool challenges tacit knowledge and will 
require substantial upgrading of technical knowledge in order to become part of farmers' management system.

The above suggests that advisors would gain from further training on the use of the FGB. A related question is whether the FGB tool can be gainfully applied without farmers knowing all the basic science behind the calculations. If the answer is no, both advisors and farmers would need to substantially upgrade their basic knowledge, which would be a challenge for the public farm advisory system.

Advisors and farmers should also be trained in estimating the risk of $\mathrm{N}$ and $\mathrm{P}$ leaching. The Excel spreadsheet provided here was based on Swedish experiences, but to get acceptance in Poland more Polish field leaching experiments might be needed. Results from $\mathrm{N}$ leaching risk assessments could be presented in the form of maps for different fields. The risk of P losses should also be evaluated for different parts of fields, based on soil type and soil P information gained from a survey, together with discussions with the farmer about water flows on the farm (Ulen, Pietrzak, Ramnerö, Strand 2016). The long-term goal should be to expose both advisors and farmers to more science-based aspects of farm management, including nutrient flows and how to enhance the use of existing nutrient sources and reduce losses. The prospect of success is good, since there is a generational shift with younger farmers entering the business, which is likely to make the farming community even more professional. This development was hinted at by the most progressive farmers in this study.

Environmental awareness is a state of mind. It consists of tacit knowledge, which can be defined as a common-sense understanding of the general phenomena of nature and of society (Puusa and Eerikäinen 2010). Creating environmental knowledge among farmers involves learning through a range of exposures via the media, peers, research projects, training, consulting, agricultural policy, EU regulations, etc. Figure 6 shows a loop with components identified by farmers' self-evaluations of how new knowledge is generated, operationalized and applied. It also includes potential effects of implementing pro-environment farming measures.

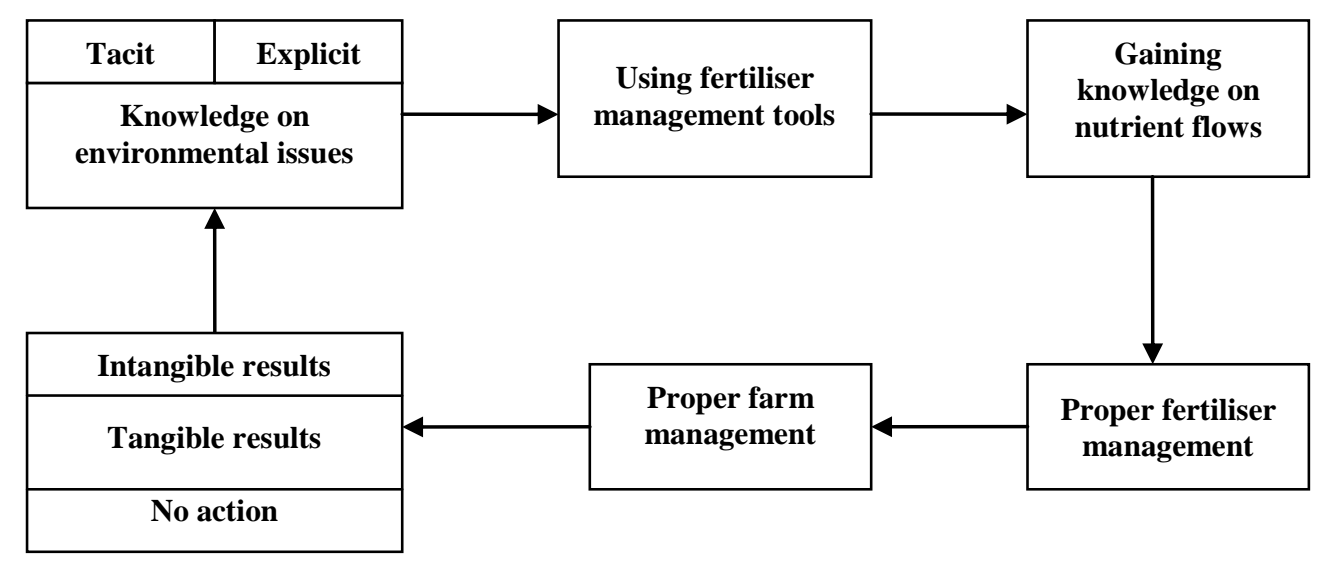

Figure 6. Agricultural management using tools to improve environmental knowledge.

The farmers can achieve tangible results such as saving money and raising productivity by using the knowledge-based tools introduced by the project. Intangible results are also important, e.g. protection of water, air and soil to counteract the ongoing eutrophication of the Baltic Sea. Tangible effects proved to affect farmers' responses most in this study. However, some farmers let their environmental awareness determine pro-active measures and have a long-term perspective. 
Raising awareness about the environmental impact of agriculture is a continuous process. Some examples can be given from the current study. Farmers were concerned about the disappearance of fish in streams and lakes in Mazovia, which might be partly attributable to too much $\mathrm{N}$ in the water. Beavers have increased in numbers as this is a protected species, and this is reported to cause severe flooding of nearby meadows. Some farmers were concerned that this might increase transport of nutrients from fields to streams. However, no farmer mentioned that flooding could cause temporary retention of nutrients and also fertilise the meadows.

Wild boars were reported to be a real menace, in particular to maize, with the compensation available not covering the economic losses. Besides, the farmers were concerned that wild boars can destroy the soil structure, with consequence for nutrient losses to waters.

Six farmers in Pomerania complained that the number of bees had decreased and claimed that this was a consequence of more use of pesticides.

From farmers' responses, it seems likely that they are only slightly familiar with parts of the $\mathrm{P}$ and $\mathrm{N}$ cycles and the interplay with removal of NPK with the harvested crop. Their argument that the processes in agricultural fields differ from those in forests/meadows is a further indication of incomplete knowledge. This raises the question of whether farmers need to become more familiar with nutrient flows and balances. The alternative is to rely on agricultural advisors and providers of fertilisers and other inputs.

\section{Conclusions and recommendations}

\section{Training material to enhance systems thinking}

Given that farmers and advisors are not quite comfortable with systems thinking and farmgate data, dissemination of such an approach has to be carefully carved out in a step-wise fashion. The amount of data involved is quite large and some must be retrieved from the literature. In the project, necessary data was provided in the form of tables supplementing the manual used for making the farm gate balance, but it was apparent that quite some experience is required to recognize improbable results caused by simple calculation mistakes.

Step 1 in the learning process could be to start with a single plant standing in the soil and look at the specific requirement for NPK and $\mathrm{pH}$ during the whole growing season. All soils store NPK in different forms and these nutrients are made available to plants at different rates, partly depending on farming practices. In addition, there is atmospheric deposition of some NPK on the soil and part of this may become available to plants. Wind and water erosion transports away varying amounts of nutrients, as does leaching. If farm-level data indicate deficiency or surplus of any nutrient, this could be remedied by applying what is lacking at the right time for the growing plant.

In step 2, farmers/advisors could try to calculate the nutrient balance for various plants, soils and soil-hydrological conditions with high relevance for farms. After such exercises, they are prepared to take on step 3 and make calculations for the entire farm, or for individual fields using e.g. their own soil surveys and literature data. At this stage, they would also be ready to correctly interpret recommendations provided by a farm-gate balance or an assessment of risks for nitrogen leaching and, ideally, have a sense of whether the result is plausible or not.

Part of the training should include exercises with improbable data being entered into the estimation tools in order to identify the faulty results these can produce. This will give the 
farmer/ advisor confidence in using both farm gate balances and nitrogen leaching risk calculations to manage their farm.

\section{Scope of training}

Since there are over one million active farmers in Poland and more than one thousand agricultural advisors (official and commercial), there are many possible ways to disseminate systems knowledge about nutrient flows and circulation. One is to take advantage of the fact that most farmers are connected to mobile phones and the internet. Instructive interactive and problem-based training material could be developed with public (government or EU) or other funding. This is in line with a proposal from HELCOM (2015).

\section{Proposed content}

A general training material must leave room for various local and farm-specific conditions. The task regarding relevant content of the training is indicated by one interviewee: "Yes, various plants need fertilisers with different composition of nutrients. But the problem is that you must have knowledge of which plant needs what. The problem is also that handbooks may advise something different. An advisor from a private company says one thing. Another advisor from the state-funded service says something else. In addition, some research has been done by fertiliser companies, so the results may not be objective". Both advisors and farmers should ideally be competent in assessing advice and applying systems thinking. At this stage, the content of a training programme could focus on making farmers confident in using tools for their decision-making.

\subsection{Suggested methods of transferring and sharing tacit knowledge}

The task ahead is to find methods where farmers agree to complement and/or adjust their broad tacit knowledge with applicable science-based knowledge. Since tacit knowledge is part of the farmer's mindset and specific to each individual, any broker of knowledge will face the problem of defining what knowledge exists and what is missing or misleading in the endeavour to improve nutrient management. In addition, local conditions differ and sciencebased data are often not exhaustive. This makes a strong case for creating a low-key system for exchange of knowledge and attitudes. One-way top-down communication may benefit only a few well-trained farmers, while more interactive methods are likely to appeal to most farmers. Farmers within a geographical area can form study groups where they exchange knowledge with peers. Their meetings could be guided by a hypothetical case to be discussed. Group discussions can be complemented with observations and study visits, and by conducting experiments. Between the meetings, members of the group could search for information and knowledge about issues that the group has identified as unclear or confusing. The study group could occasionally invite a guest to answer their queries. Creating such expert and knowledge networks would be an investment in continued learning.

Training of advisors could apply the same knowledge-generating method as described above for farmers. Advisors also embrace tacit knowledge to a large extent and would gain from a form of training where peers exchange information and discuss attitudes in a nonthreatening manner. Advisors may need to receive some kind of certification, which may require some kind of knowledge check or testing. 


\section{Acknowledgements}

Our sincere thanks to Henryk Zemsta, Dorota Skura and Renata Smagacka who carried out and assisted with evaluation of the first round of interviews, as well as to Katarzyna Radtke.

\section{Funding}

The Swedish Foundation BalticSea 2020 is greatly acknowledged for financial support.

\section{References}

Agrotec and Evaluators. 2009. Evaluation of the Implementation of the Farm Advisory System. Final Report - Evaluation Part. European Commission, Agrotec and Evaluators, December 2009, http://ec.europa.eu/agriculture/eval/reports/fas/report_eval_en.pdf, (accessed March 3, 2016).

AKIS. 2012. Agricultural Knowledge and Innovation Systems in Transition - a Reflection Paper. Standing Committee on Agricultural Research (SCAR), Collaborative Working Group AKIS, Brussels, 29-33.

Ambrosini, V., and Bowman, C. 2001. Tacit Knowledge: Some Suggestions for Operationalization. Journal of Management Studies 38(6):811-829.

Brokensha, D., Warren, D.M., and Werner, O. (ed.) 1980. Indigenous knowledge systems and development. Lanham, University Press of America.

Council Regulation (EC) 2005. No 1698/2005 of 20 September 2005 on support for rural development by the European Agricultural Fund for Rural Development (EAFRD).

Council Directive 91/676/EEC of 12 December 1991 concerning the protection of waters against pollution caused by nitrates from agricultural sources.

Drangert, J-O., and Kiełbasa, B. 2016. Self-evaluation and risk analysis by farmers concerning losses of nutrient and low cost remedial measures. Report 2. Post-project interview study. BalticSea2020.

Drangert, J-O., and Kiełbasa, B. 2015. Analysis of advisors' collaboration with farmers. Report 3. Final report of questionnaire study. Baltic2020.

Drangert, J-O. 2014. Self-evaluation and risk analysis by farmers concerning losses of nutrient and low cost remedial measures. Report 1. Pre-project interview study. BalticSea2020.

Hassard, J., and Kelemen, M. 2001. Production and Consumption in Organizational Knowledge: The Case of the "Paradigms Debate". Organization 9(2):331-355.

Hendrix, P.F., Coleman, D.C., and Crossley, D.A. Jr. 1992. Using Knowledge of Soil Nutrient Cycling Process to Design Sustainable Agriculture. Journal of Sustainable Agriculture 2(3):63-82.

HELCOM 2015. Manure nutrient content in the Baltic Sea countries. Workshop organized by Ministry of the Environment. Vantaa, Finland.

Kiełbasa, B., and Kania, J. 2014. The capability of extension and advisory services to bridge research and knowledge needs of farmers: Demonstration Farms for Transfer of Knowledge - Case study from Poland. Report for AKIS on the ground: focusing knowledge flow systems (WP4) of the PRO AKIS project, http://proakis.eu/sites/www.proakis.eu/files/Topic\%202-\%20Poland.pdf, (accessed February 18, 2016). 
Klerkx, L., Hall, A., and Leeuwis, C. 2009. Strengthening Agricultural Innovation Capacity: Are Innovation Brokers the Answer? United Nations University - Maastricht Economic and social Research and training centre on Innovation and Technology, Netherlands, Working Paper Series 019, 8-9.

Lionberger, H.F. 1961. Adoption of new ideas and practices. Ames, The Iowa State University Press.

Nonaka, I., and Nishiguchi, T. 2001. Knowledge Emergence. Social, Technical and Evolutionary Dimensions of Knowledge Creation. Oxford University Press, Oxford.

Nonaka, I., and von Krogh, G. 2009. Tacit Knowledge and Knowledge Conversion: Controversy and Advancement in Organizational Knowledge Creation Theory. Organization Science 20(3):635-652.

Oenema, O., and Pietrzak, S. 2002. Nutrient Management in Food Production: Achieving Agronomic and Environmental Targets. AMBIO: A Journal of the Human Environment 31(2):159-168.

Ulen, B., and Kalisky, T. 2005. Water and phosphorus problems in an agricultural catchment - need for natural research for implementation of the EU Water Framework Directive. Environmental Science and Policy 8 (5):477-484.

Ulen, B., Pietrzak, S., Ramnerö, B., Strand, L. 2016. Agricultural soil acidity and phoshporus leaching risk at farm level in two focus areas. Acta Agriculturae Scandinavica, section B - Soil and Plant Science 66(4):359-368.

Polanyi, M. 1966. The Tacit Dimension. Routledge and Kegan Paul, London.

Puusa, A., Eerikäinen, M. 2010. Is Tacit Knowledge Really Tacit? Electronic Journal of Knowledge Management 8(3):307-318.

Rogers, E. 1986. Models of knowledge transfer: Critical perspectives. In Knowledge Generation, Exchange, and Utilization. G.M. Beal, W. Dissanayake and S. Konoshima, 37-60. Boulder, Westview Press.

Ramnerö, B. 2015. Self-evaluation of the Risk of Enhanced Nutrient Leaching by Polish Farmers - Nutrient balances, Soil maps, Farm walks and other tools. SLU, Swedish University of Agricultural Sciences, Faculty of Natural Resources and Agricultural Sciences, Department of Soil and Environment. Uppsala, Sweden.

Schon, D.A. 1971. Beyond the stable stage. New York, Random House.

Swanson, B.E. 2008. Global Review of Good Agricultural Extension and Advisory Service Practices. Food and Agriculture Organization (FAO) of The United Nations, Rome:6-7.

Taylor, H. 2007. Tacit Knowledge: Conceptualizations and Operationalizations. International Journal of Knowledge Management 3(3):60-73. 